\title{
DEVELOPMENT AND CHARACTERIZATION OF NEVIRAPINE LOADED AMORPHOUS SOLID DISPERSIONS FOR SOLUBILITY ENHANCEMENT
}

\author{
GAGANDEEP SINGH, NAVJOT SINGH, RANDEEP KUMAR AND NEENA BEDI*
}

Department of Pharmaceutical Sciences, Guru Nanak Dev University, Amritsar, Punjab, India. Email: neena.pharma@gndu.ac.in

Received: 13 May 2019, Revised and Accepted: 24 June 2019

\section{ABSTRACT}

Objective: The present study entails the development of nevirapine (NVP)-loaded solid dispersions for improvement of solubility and in vitro profile.

Methods: Solid dispersions were prepared through blending with a hydrophilic polymer and Vitamin E tocopherol polyethylene glycol succinate (TPGS) using the solvent evaporation method. The optimized formulations were characterized by Fourier transform infrared spectroscopy, differential scanning calorimetry, X-ray diffraction, and morphological investigations by scanning electron microscopy. The optimized formulation was converted into fast dissolving tablets (FDTs) through direct compression technique and was characterized for pre- and post-compression parameters. Both amorphous dispersions and FDTs were evaluated for in vitro drug release.

Results: NVP showed pH-dependent solubility in different $\mathrm{pH}$ media. Above $0.002 \% \mathrm{w} / \mathrm{v}$ Vitamin E TPGS, a linear relationship was observed between the NVP solubility and Vitamin E TPGS concentration. According to the study, the most suitable formulation was NVP:Vitamin E TPGS (1:0.75) in $30 \mathrm{ml}$ solvent with a drug release of $82.96 \%$ in $2 \mathrm{~h}$. The analysis of dissolution data of optimized formulation indicated the best fitting with the Higuchi model. FDTs exhibited faster drug release of about $50 \%$ in 5 min indicating desired attributes for the immediate dosage form.

Conclusion: The present study vouches for better in vitro profile of NVP from solid dispersion based FDTs.

Keywords: Nevirapine, Vitamin E tocopherol polyethylene glycol succinate, Solid dispersion, Fast dissolving tablets.

(C) 2019 The Authors. Published by Innovare Academic Sciences Pvt Ltd. This is an open access article under the CC BY license (http://creativecommons. org/licenses/by/4. 0/) DOI: http://dx.doi.org/10.22159/ajpcr.2019.v12i8.34097

\section{INTRODUCTION}

A large percentage of potential drug candidates suffer from low aqueous solubility and dissolution rate. This results in low drug concentrations at the absorption sites and hence, low oral bioavailability [1]. Moreover, the poor oral bioavailability arising from poor aqueous solubility makes drug research and development even more difficult. There is a great interest to develop efficient, reliable, economical, and scalable methods to increase the oral bioavailability of poorly water-soluble drugs. Various approaches have been developed with a focus on enhancement of the solubility, dissolution rate, and oral bioavailability of poorly water-soluble drugs such as complex formation, salt formation, solid dispersion, nanosuspensions, cocrystallization, eutectic mixture, solid solutions, particle size reduction (micronization), cosolvancy, supercritical fluid process, and use of solid adjuvant such as surfactants [2-5]. The preparation of solid dispersions in pharmaceutically acceptable water-soluble polymers has been shown to be particularly effective in enhancing the rate of dissolution and oral bioavailability. BCS Class II drugs (high permeability and low solubility) are most likely to benefit from solid dispersion formulation, as once they are solubilized in the gastrointestinal tract, they will achieve an absorption profile similar to that of a Class I drugs (high permeability and high solubility) [5]. In recent years, many water-soluble polymers have been employed for preparing binary and ternary solid dispersions, such as polyethylene glycol (PEG), polyvinylpyrrolidone, HPMC, poloxamer, tocopherol polyethylene glycol succinate (TPGS), Gelucire, and Labrasol [3,4]. Nevirapine (NVP), 2-cyclopropyl-7-methyl-2,4,9,15tetraazatricyclo [9.4.0.03,8] pentadeca-1(11),3,5,7,12,14 hexaen-10-one (Fig.1), a reverse transcriptase (RT) inhibitor of human immunodeficiency virus (HIV-1) belongs to BCS-II system. NVP inhibits replication of HIV-1 by interfering with viral RNA-directed DNA polymerase (RT) [6].

Surfactants have historically been used for enhancing solubility and bioavailability of lipophilic compounds. TPGS is a non-ionic surfactant, synthesized from the lipid-soluble antioxidant, $\alpha$-tocopherol (Vitamin E) by grafting to a PEG oligomer through a succinate di-ester linker and has been reported to increase the bioavailability of poorly water-soluble drugs by enhancing their solubility and permeability $[7,8]$. Based on all these considerations, the aim of the present study was to prepare a solid dispersion of NVP using Vitamin E TPGS as a drug carrier to enhance the solubility and dissolution profile of the drug.

\section{MATERIALS AND METHODS}

\section{Materials}

D- $\alpha$ TPGS (Vitamin E TPGS) was purchased from Sigma Laboratories Pvt., Ltd., India; NVP was obtained as a gift sample from Cipla Pharmaceuticals Ltd., India. Triple distilled water (Rions India Lab Water Systems Pvt., Ltd.) was used throughout the study. All other reagents (chemicals and solvents) used were of analytical grade.

\section{Methods}

High-performance liquid chromatographic (HPLC) analysis of NVP Reversed-phase column based HPLC method was used. The system consisted of a pump configured to Lab Solutions software with autoinjecting facility. The HPLC was equipped with a column oven and the analytical column used was enable $\mathrm{C}-18 ; 4.6 \mathrm{~mm} \times 250 \mathrm{~mm} ; 5 \mu \mathrm{m}$. The mobile phase used was methanol:water $(50: 50 \mathrm{v} / \mathrm{v})$ at a flow rate of $0.9 \mathrm{ml} / \mathrm{min}$ in an isocratic mode. The prepared mobile phase was sonicated (Ultra cleaner, LABPRO International, India) and filtered with a $0.22 \mu \mathrm{m}$ filter membrane (Millipore, India) before analysis. The detection was done by the SPD-M 20A photodiode array detector at $284 \mathrm{~nm}$. The data processing and acquisition were done on Lab Solutions System software (version 3.1.05.9) [9].

\section{Solubility determination in different $\mathrm{pH}$ solutions}

The solubility of the NVP was determined in different media such as distilled water, $0.1 \mathrm{~N}$ hydrochloric acid $(\mathrm{pH} 1.2)$, phosphate buffer of 
$\mathrm{pH} 4.6, \mathrm{pH} 6.8$, and $\mathrm{pH}$ 7.2. Excess amount of drug, i.e., $10 \mathrm{mg}$ of NVP was added to a glass vial containing $5 \mathrm{ml}$ of medium and rotated for $72 \mathrm{~h}$ on a water bath shaker (Narang Scientific Works, New Delhi) at room temperature [10]. The content of each conical flask was filtered through $0.22 \mu \mathrm{m}$ membrane filter and the filtrates were analyzed by optimized HPLC method. The solubility studies were carried out in triplicate to endorse the reproducibility of results.

\section{Phase solubility studies}

An excess amount of NVP (10 mg) was added to $5 \mathrm{ml}$ of distilled water containing increasing concentrations of Vitamin E TPGS (0.005$2 \% \mathrm{w} / \mathrm{v}$ ). The flasks were sealed and shaken at room temperature for $72 \mathrm{~h}$ on a water bath shaker and after attainment of equilibrium; the samples were filtered through a $0.2 \mu \mathrm{m}$ membrane filter (Millipore, India). The solubilized amount of drug was determined using the optimized HPLC method, and all readings were taken in triplicate [11,12].

\section{Preparation of physical mixtures (PMS) of NVP with Vitamin E TPGS}

PMs were prepared by mixing accurate weight of NVP with Vitamin E TPGS in drug to polymer ratio of 1:0.25, 1:0.50, and 1:0.75 (PM1, PM2, and PM3, respectively). The mixture was pulverized and then mixed thoroughly in a mortar with a pestle until homogenous mixture was obtained. The mixture was passed through sieve no. 42 and stored in a closed container till further use.

\section{Preparation of solid dispersions of NVP with Vitamin E TPGS}

Solid dispersions of NVP with Vitamin E TPGS were prepared by the solvent evaporation method [13]. Solid dispersions of NVP in Vitamin E TPGS containing three different drugs to polymer ratios $(1: 0.25,1: 0.5$, and 1:0.75) and using three different volumes of solvent $(10 \mathrm{ml}, 20 \mathrm{ml}$, and $30 \mathrm{ml})$ were prepared. Vitamin E TPGS was dissolved in methanol with constant stirring until a clear solution was obtained, NVP was incorporated into the solution, and stirring was continued for $45 \mathrm{~min}$. The solvent was evaporated at $60^{\circ} \mathrm{C}$ under vacuum in a rotary evaporator (Heidolph 2 Laborota 4001, India). The resultant dispersions were placed in refrigerator for $12 \mathrm{~h}$ to obtain solidified dispersions. After solidification, it was pulverized and sieved through sieve no. 42 and stored in a desiccator till further use.

\section{Characterizations of solid dispersions Fourier transform infrared (FT-IR) spectroscopy}

FT-IR spectra of different samples, namely, NVP, Vitamin E TPGS, physical mixture, and solid dispersions were recorded with FTIR spectrophotometer (PerkinElmer, USA) [14]. The samples were analyzed in a fingerprint range of 4000-450 $\mathrm{cm}^{-1}$.

\section{Differential scanning calorimetry (DSC)}

Thermal data analysis of the DSC thermogram was conducted using DSC (Q20 V24.2 Build 107, TA Instruments) software. Approximately 5 mg of NVP, PMs and solid dispersions were placed in a sealed aluminum pan and heated at a scanning rate of $2^{\circ} \mathrm{C} / \mathrm{min}$ from $20^{\circ} \mathrm{C}$ to $300^{\circ} \mathrm{C}$ [15].

\section{$X$-ray diffraction (XRD) study}

The powder XRD patterns of NVP, PMs, and solid dispersion systems were recorded using an X-ray diffractometer (Rigaku Analytical XRD, India). XRD studies were performed under the following conditions: $\mathrm{CuK}_{\infty}$ line $(\lambda=0.154 \mathrm{~nm})$, voltage $40 \mathrm{kV}$, current $35 \mathrm{~mA}$, and $2 \theta$ degrees at ambient temperature [16]. The samples were analyzed over the $2 \theta$ range from $5^{\circ}$ to $45^{\circ}$ at a fixed X-ray source of $100 \mathrm{~cm}$.

\section{Scanning electron microscopy (SEM)}

The surface topography was analyzed with a scanning electron microscope (Carl Zeiss SUPRA 55) operated at an acceleration voltage of $5 \mathrm{kV}$. The SEM analysis was carried out to study the surface morphology of NVP, its PMs, and the solid dispersions.
In vitro dissolution studies

NVP, PMs, and solid dispersions equivalent to $50 \mathrm{mg}$ of the drug were used for studying the rate and extent of drug dissolution. The study was performed using USP Type II (paddle type) dissolution apparatus (Lab India Dissolution Test Apparatus, DISSO 2000, India) maintained at $37 \pm 0.5^{\circ} \mathrm{C}$ at $75 \mathrm{rpm}$, using $900 \mathrm{ml}$ of distilled water as dissolution medium. The test samples were filtered through $0.2 \mu \mathrm{m}$ membrane filter and analyzed using HPLC method. Percent dissolution efficiency (DE) for each formulation was computed as the percent ratio of area under the dissolution curve up to the time $t$, to that of the area of the rectangle described by $100 \%$ dissolution at the same time (Equation 1) [17]

$D E=\left(\frac{\int_{0}^{t} y \cdot d t}{y 100 . t}\right) 100$

Other dissolution parameters such as dissolution rate $\mathrm{DP}_{5}, \mathrm{DP}_{30}$, and $\mathrm{DP}_{120}$ were also calculated.

\section{Mathematical modeling of release kinetics}

The in vitro drug release data of the optimized solid dispersion were fitted to various release kinetic models, namely, zero-order, first-order, Higuchi, and Korsmeyer-Peppas model employing the following set of equation [18].

Zero-order kinetic model

$\mathrm{M}_{0}-\mathrm{M}_{\mathrm{t}}=\mathrm{K}_{0} \mathrm{t}$

First-order model

$\ln \left(\mathrm{M}_{0} / \mathrm{M}_{\mathrm{t}}\right)=\mathrm{K}_{1} \mathrm{t} / 2.303$

Higuchi mode

$\mathrm{M}_{\mathrm{t}}=\mathrm{K}_{\mathrm{H}} \sqrt{\mathrm{t}}$

Korsmeyer-Peppas model

$\mathrm{M}_{\mathrm{t}} / \mathrm{M}_{\infty}=\mathrm{Kt}^{\mathrm{n}}$

Where, $\mathrm{M}_{0}, \mathrm{M}_{\mathrm{t}}$, and $\mathrm{M}_{\infty}$ correspond to the drug amount at zero, dissolved at a particular time, $\mathrm{t}$, and at infinite time, respectively. Various other terms, namely, $\mathrm{K}_{0}, \mathrm{~K}_{1} \mathrm{~K}_{\mathrm{H}}$, and $\mathrm{K}$ refer to the release kinetic constants obtained from the linear curves of zero-order, first-order, Higuchi model, and Korsmeyer-Peppas, respectively.

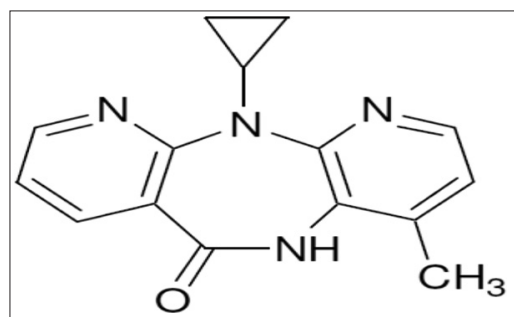

Fig. 1: Structure of nevirapine

Table 1: Composition of various ingredients used to prepare FDTs

\begin{tabular}{lllll}
\hline S. No. & Ingredients (mg) & F1 (\%) & F2 (\%) & F3 (\%) \\
\hline 1. & Solid dispersion & $350(70)$ & $350(70)$ & $350(70)$ \\
2. & Sodium starch glycolate & $50(10)$ & $60(12)$ & $70(14)$ \\
3. & Microcrystalline cellulose & $10(2)$ & $20(4)$ & $30(6)$ \\
4. & Mannitol & $30(6)$ & $20(4)$ & $15(3)$ \\
5. & Talc & $30(6)$ & $20(4)$ & $15(3)$ \\
6. & Magnesium stearate & $30(6)$ & $30(6)$ & $20(4)$ \\
Total weight of tablet (mg) & 500 & 500 & 500 \\
\hline
\end{tabular}

FDTs: Fast dissolving tablets 
Preparation of fast dissolving tablets (FDTs) of NVP solid dispersion

FDTs of NVP were prepared using different excipients, i.e., super disintegrants, binders, lubricants, and then evaluated for various parameters to select the best combination to prepare NVP tablets [19]. A series of trials were taken to formulate an optimized formulation with sufficient mechanical strength, disintegration time, and dissolution profiles (Table 1). The batches F1, F2, and F3 were prepared, and the uniform mass was sieved through mesh \#42. The powder mass was also characterized by flow properties by different techniques. However, after the characterization of powder, tablets were prepared using direct compression method and evaluated by various evaluation tests for tablets.

\section{Evaluation of FDTs}

Pre-compression evaluation for the powder blend

Various micro metrics parameters such as angle of repose by static funnel method, bulk, and tapped density by tapping method were determined. The values so obtained were put into standard equations (Equations 6 and 7) to determine the compressibility index and Hausner's ratio for determination of the optimum flowability of the solid dispersion powders [19-21].

Carr's compressibility Index $=\frac{\text { Tapped density }- \text { Bulk density }}{\text { Tapped density }} \times 100$

Hausner's Ratio $=\underline{\text { Tapped density }- \text { Bulk density }}$

$$
\text { Bulk density }
$$

\section{Post-compression evaluations}

Various post-compression parameters of tablets such as hardness, thickness, weight variation, drug content, friability, wetting time, water absorption ratio, and disintegration test were determined as per the standard USP monographs [22-26].

\section{RESULTS AND DISCUSSION}

\section{Solubility studies in different $\mathrm{pH}$ solutions}

The solubility of NVP was determined at $25 \pm 0.5^{\circ} \mathrm{C}$, in distilled water and wide range of $\mathrm{pH}$ solutions of $0.1 \mathrm{~N} \mathrm{HCl} \mathrm{(pH} \mathrm{1.2),} \mathrm{phosphate} \mathrm{buffer}$ of $\mathrm{pH} 4.6$, $\mathrm{pH}$ 6.8, and $\mathrm{pH}$ 7.2. As NVP is a weekly basic drug (pK 2.8), an increase in solubility was anticipated with a decrease in $\mathrm{pH}$ as shown in Fig. 2 . The $\mathrm{pH}$ solubility profile indicated a gradual decline in solubility with an increase in $\mathrm{pH}$ from $1.2(1.35 \mathrm{mg} / \mathrm{ml})$ to $4.6(0.229 \mathrm{mg} / \mathrm{ml})$ and remained steady at $\mathrm{pH} 7$ and $7.2(0.1 \mathrm{mg} / \mathrm{ml})$. These results revealed that the solubility of NVP is $\mathrm{pH}$ dependent, which is in accordance with the reported literature [27-30].

\section{Phase solubility studies}

The appropriate amount of Vitamin E TPGS was dissolved in water and various concentrations in the range of $0.002-2 \% \mathrm{w} /$ v were prepared. Phase solubility studies indicated that solubility of NVP increased with increase in the concentration of Vitamin E TPGS. The critical micelle concentration of Vitamin E TPGS was found to be $0.2 \mathrm{mg}(0.002 \% \mathrm{w} / \mathrm{v})$ [31]. At about $0.002 \% \mathrm{w} / \mathrm{v}$ Vitamin E TPGS concentration, the micellization occurs, leading to increased accommodation of NVP molecules in the micelles with enhancement in solubility as depicted in Fig. 3.

\section{In vitro dissolution studies}

In vitro drug release studies are important assessment tools to determine systemic drug availability in biological media. The in vitro release profile of NVP, PMs, and the optimized solid dispersions are depicted in Figs. 4 and 5, respectively. The incomplete release profile of pure drug $(20.43 \%)$ in $2 \mathrm{~h}$ could be attributed to the $\mathrm{pH}$-dependent solubility of NVP, suggesting a strong need to enhance its dissolution. Moreover, the rate of dissolution from PMs PM1, PM2, and PM3 was found to be $36.58 \%, 37.90 \%$, and $44.96 \%$, in $2 \mathrm{~h}$, respectively. The dry mixing in PMs has been reported to bring drug in close contact with the hydrophilic polymers, and the increased dissolution rate can thus be explained as a result of increased wettability and dispersibility of drug [32].

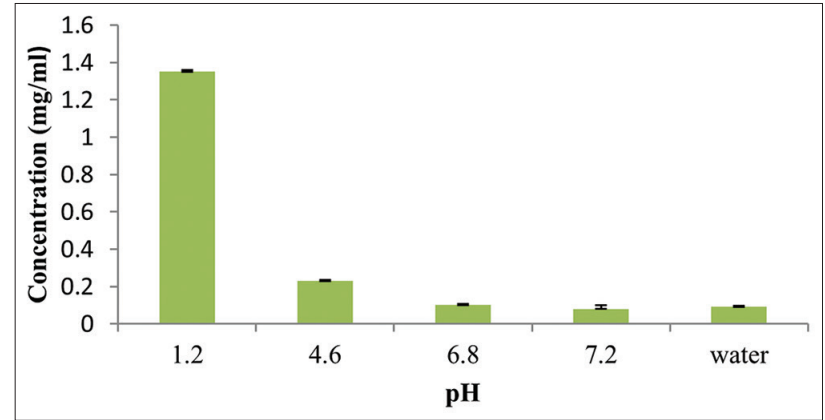

Fig. 2: Solubility studies of nevirapine in different $\mathrm{pH}$ solutions (mean \pm standard deviation $\mathrm{n}=3$ )

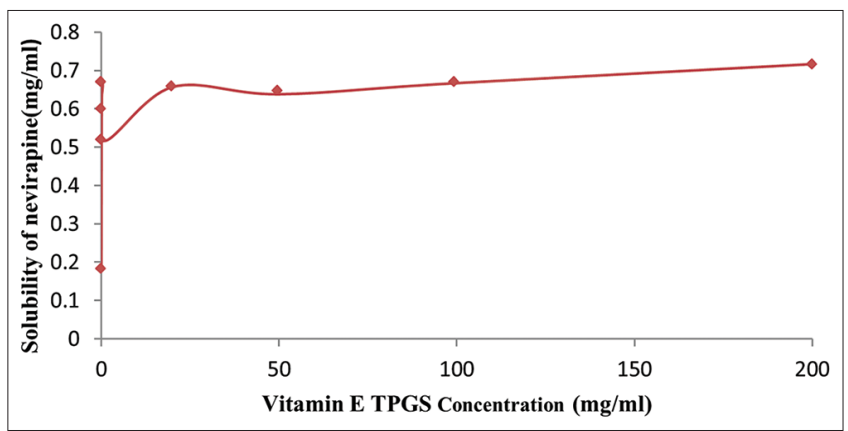

Fig. 3: Phase solubility analysis of nevirapine with Vitamin E tocopherol polyethylene glycol succinate

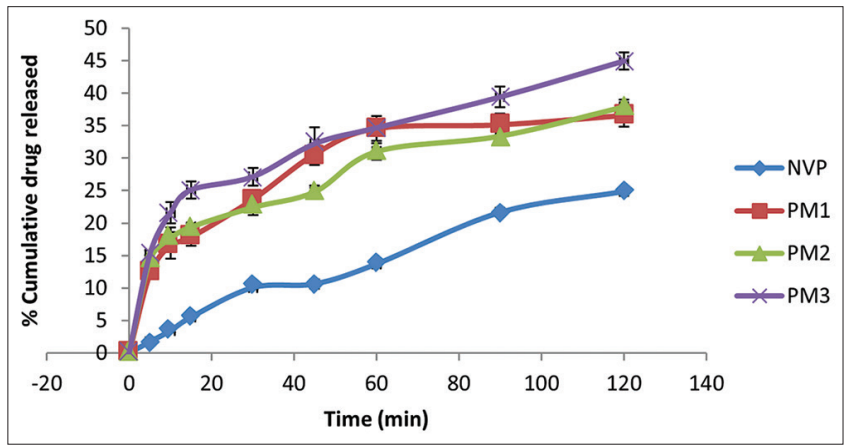

Fig. 4: In vitro dissolution profile of nevirapine and its corresponding physical mixtures with Vitamin E tocopherol polyethylene glycol succinate

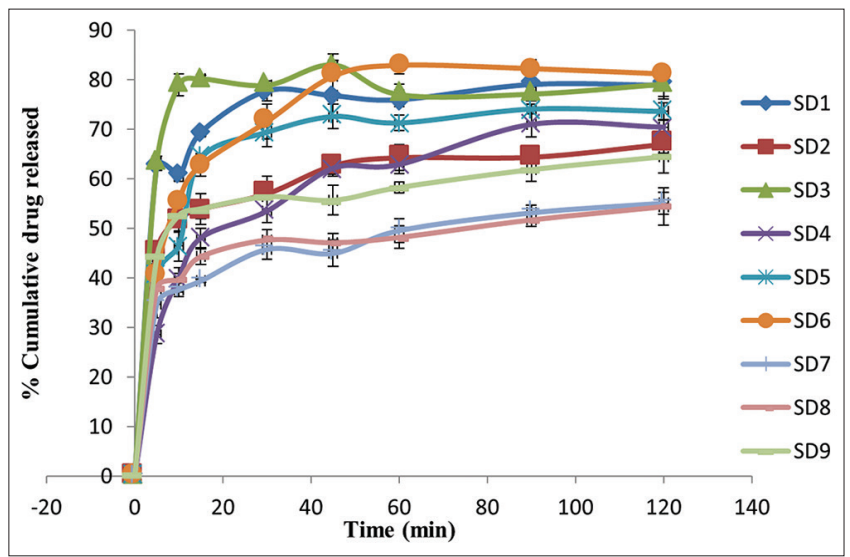

Fig. 5: In vitro dissolution profile of prepared solid dispersions in optimized media at $37 \pm 0.5^{\circ} \mathrm{C}$

Solid dispersions of NVP in Vitamin E TPGS containing three different ratios of drug and polymer (1:0.25, 1:0.50, and 1:0.75) and also using 
Table 2: Dissolution parameters of solid dispersions of NVP and Vitamin E TPGS

\begin{tabular}{|c|c|c|c|c|c|}
\hline Solid dispersion batches & $\mathrm{DE}_{30(\min )}$ & $\mathrm{DE}_{60(\min )}$ & $\mathrm{DP}_{5(\mathrm{~min})}$ & $\mathrm{DP}_{30(\mathrm{~min})}$ & $\mathrm{DP}_{120(\mathrm{~min})}$ \\
\hline SD1 & 63.09 & 69.94 & 62.58 & 77.71 & 78.86 \\
\hline SD2 & 46.95 & 53.62 & 45.40 & 56.90 & 66.88 \\
\hline SD3 & 70.11 & 75.25 & 63.24 & 78.90 & 79.08 \\
\hline SD4 & 41.30 & 50.97 & 28.53 & 55.46 & 70.40 \\
\hline SD5 & 53.19 & 62.31 & 40.47 & 69.37 & 73.56 \\
\hline SD6 & 54.92 & 66.93 & 41.01 & 71.53 & 81.15 \\
\hline SD7 & 36.57 & 41.41 & 34.63 & 45.71 & 55.04 \\
\hline SD9 & 48.18 & 52.32 & 44.14 & 56.35 & 64.44 \\
\hline
\end{tabular}

TPGS: Tocopherol polyethylene glycol succinate, NVP: Nevirapine

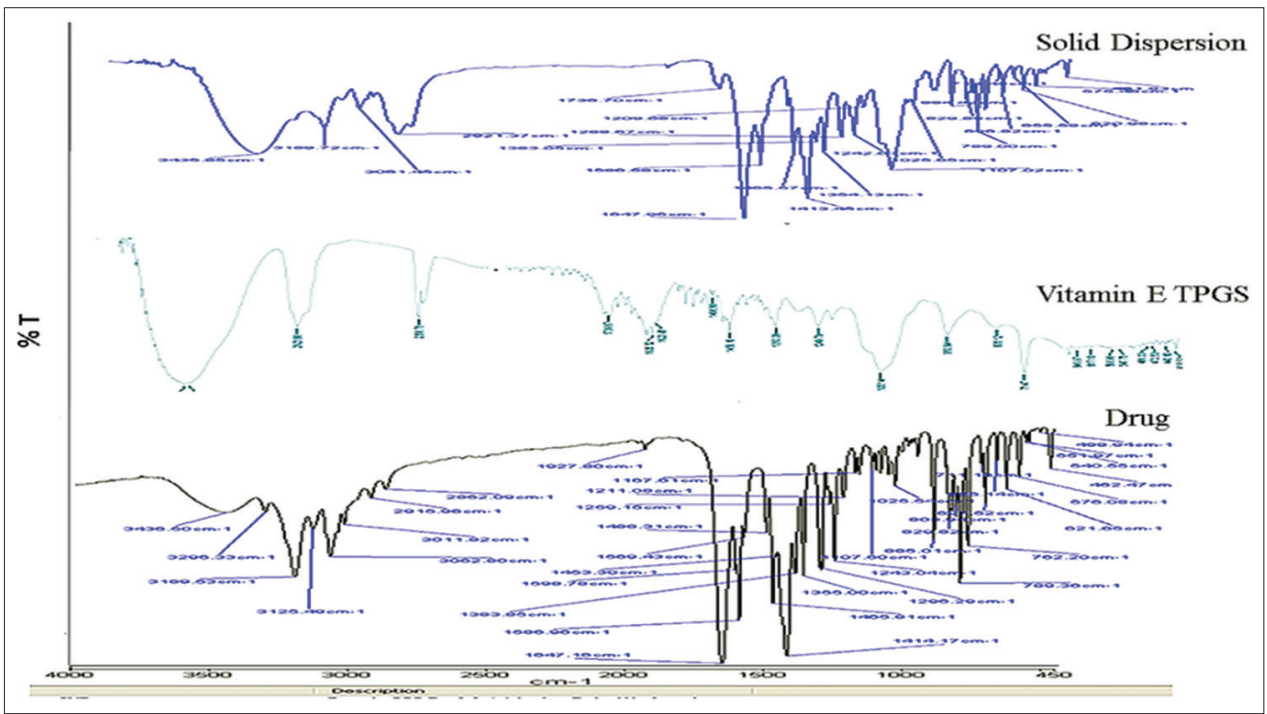

Fig. 6: Fourier transform infrared spectrograms overlay of nevirapine, Vitamin E tocopherol polyethylene glycol succinate, and optimized solid dispersion (SD3)

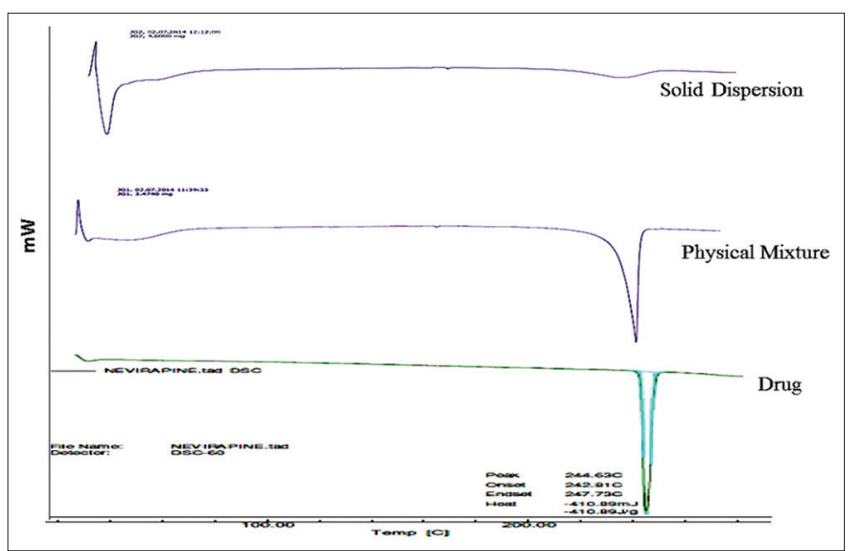

Fig. 7: Differential scanning calorimetry overlay of nevirapine, physical mixture, and optimized solid dispersion (SD3)

three different amounts of solvent $(10 \mathrm{ml}, 20 \mathrm{ml}$, and $30 \mathrm{ml})$ were fabricated. The solid dispersions SD1, SD2, and SD3 (having drug to polymer ratios 1:0.25-1:0.75 and solvent $10 \mathrm{ml}$ ) showed the maximum release of $66.93 \%, 78.85 \%$, and $82.96 \%$ in $2 \mathrm{~h}$, respectively. In solid dispersions SD4, SD5, and SD6, the drug to polymer ratios vary from 1:0.25 to 1:0.75, while the solvent amount of $20 \mathrm{ml}$ was used. The solid dispersions SD4, SD5, and SD6 showed the maximum release of 70.40\%, $73.56 \%$, and $81.15 \%$, respectively, in $2 \mathrm{~h}$, i.e., $\mathrm{DP}_{120}$. The solid dispersions SD7, SD8, and SD9 (having drug to polymer ratios 1:0.25-1:0.75 and solvent used $30 \mathrm{ml}$ ) showed the maximum release of $55.04 \%, 54.35 \%$, and $64.44 \%$, respectively, in $2 \mathrm{~h}$, i.e., $\mathrm{DP}_{120}$. Moreover, the enhancement

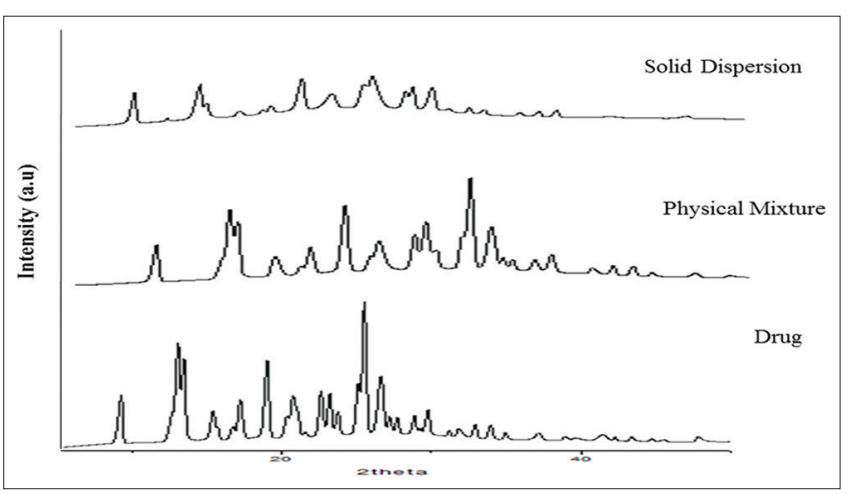

Fig. 8: X-ray diffraction overlay of nevirapine, physical mixture, and optimized solid dispersion

of dissolution of NVP from drug carrier systems can be described by several factors like lack of crystallinity, i.e., amorphization, increased wettability, and dispersibility and micellization of Vitamin E TPGS [31].

Furthermore, from the DE, it was observed that SD3 showed $\mathrm{DE}_{30}$ of $70.11 \%$, while SD6 shows $\mathrm{DE}_{30}$ of $54.96 \%$ (Table 2). Thus, SD3 ratio was selected to carry out for further formulation development studies.

Characterization of NVP, Vitamin E TPGS, PMs, and optimized solid dispersion

FT-IR spectroscopy

Results of spectroscopic investigations revealed no inherent physical interactions as no major shifting of peaks were observed in the physical 
Table 3: Pre-compression parameters of prepared formulations

\begin{tabular}{|c|c|c|c|c|c|}
\hline Batch code & Angle of repose $(\theta)$ & Bulk density $\left(\mathrm{g} / \mathrm{cm}^{3}\right)$ & Tapped density $\left(\mathrm{g} / \mathrm{cm}^{3}\right)$ & Hausner's ratio & Compressibility index (\%) \\
\hline F1 & $31.38 \pm 1.67$ & $0.3846 \pm 0.07$ & $0.4545 \pm 0.083$ & $1.181 \pm 0.038$ & $15.37 \pm 1.34$ \\
\hline F2 & $32.41 \pm 1.98$ & $0.3807 \pm 0.05$ & $0.4500 \pm 0.032$ & $1.182 \pm 0.046$ & $15.40 \pm 2.34$ \\
\hline F3 & $31.79 \pm 1.56$ & $0.3830 \pm 0.45$ & $0.4527 \pm 0.034$ & $1.181 \pm 0.036$ & $15.39 \pm 2.49$ \\
\hline
\end{tabular}

Table 4: Post-compression parameters of prepared formulations

\begin{tabular}{lllllll}
\hline $\begin{array}{l}\text { Batch } \\
\text { code }\end{array}$ & $\begin{array}{l}\text { Disintegration } \\
\text { time (seconds) }\end{array}$ & Hardness $\left(\mathbf{k g} / \mathbf{c m}^{3}\right)$ & Friability $(\% \mathbf{w} / \mathbf{w})$ & $\begin{array}{l}\text { Wetting } \\
\text { time (seconds) }\end{array}$ & $\begin{array}{l}\text { Water absorption ratio } \\
\text { (\% w/w) }\end{array}$ & Drug content (\%) \\
\hline F1 & $120 \pm 5.5$ & $3.2 \pm 1.2$ & $0.82 \pm 0.6$ & $46 \pm 2$ & $41.44 \pm 2.50$ & $93.05 \pm 5.65$ \\
F2 & $90 \pm 4.54$ & $3.3 \pm 1.6$ & $0.86 \pm 0.3$ & $48 \pm 3$ & $41.20 \pm 2.30$ & $95.74 \pm 7.39$ \\
F3 & $40 \pm 2.65$ & $3.5 \pm 1.3$ & $0.70 \pm 0.4$ & $44 \pm 2$ & $45.45 \pm 1.50$ & $97.16 \pm 6.29$ \\
\hline
\end{tabular}

mixture of drug with Vitamin E TPGS (Fig. 6). Furthermore, the major stretching and bending peaks were observed in the prepared formulation indicating the physical compatibility of the drug with the polymer [33,34].

DSC

The DSC endotherms of NVP, physical mixture, and the optimized solid dispersion are shown in Fig. 7. NVP shows an endothermic peak at $247.43^{\circ} \mathrm{C}$ while the physical mixture showed endothermic peaks of drug and TPGS at $246^{\circ} \mathrm{C}$ and $39^{\circ} \mathrm{C}$, respectively [35]. The intensity of endothermic peak corresponding to the melting point of drug was decreased in the optimized solid dispersion formulation, suggesting the molecularly dispersed state of NVP in the solid dispersions. This observation confirms the amorphous nature of NVP after encapsulating in the Vitamin E TPGS [36].

\section{XRD studies}

XRD of NVP showed characteristicpeaks at various diffraction angles (20) of $9.2^{\circ}, 13.1^{\circ}, 19.04^{\circ}$, and $25.54^{\circ}$, which confirmed its crystalline nature (Fig. 8). The XRD pattern of the physical mixture showed characteristics diffraction peaks of $14^{\circ}, 24^{\circ}$, and $35^{\circ}$, but with lesser intensity. However, the absence of sharp diffraction peaks was noticeable in optimized solid dispersions, which indicate the amorphous embedding or molecular dispersibility of drug within polymer matrix [37].

\section{SEM}

NVP existed as partial crystalline material with soft edges (Fig. 9a) while Vitamin E TPGS existed as waxy solid which may melt at $37^{\circ} \mathrm{C}$; hence, it was quite difficult to obtain the SEM images. In the physical mixture, the characteristic NVP crystals which were mixed with Vitamin E TPGS particles or adhered to their surface were clearly detectable (Fig. 9b). In the solid dispersion, the surface is slightly rougher compared with NVP and the particle size is much bigger than NVP, suggesting that the surface morphology of solid dispersion got changed, i.e., particle size decreases (Fig. 9c). Therefore, the increased surface area and the close contact between the hydrophilic polymer and the drug might be responsible for the enhanced dissolution of the solid dispersion [38].

\section{Evaluation of FDTS}

Pre-compression evaluation of the powder blend

Pre-compression evaluation studies were carried out to ensure the flow properties of the powder blend as shown in Table 3 experimental findings revealed that the powder blends of all formulations (F1, F2, and F3) possess good flow properties and hence, formulated into FDTs.

Post-compression evaluation of the powder blend

The tablets obtained after compression were evaluated on various parameters to determine their quality and to ensure that the resultant product meets all necessary criteria required for the FDTs (Table 4).

The wetting time and water absorption ratio indicate the capacity of the super disintegrants to absorb water and completely wet the tablet at the earliest time possible, which are the significant characteristics of
Table 5: Post-compression parameters of formulation F3

\begin{tabular}{ll}
\hline Evaluation parameters & Results \\
\hline Hardness & $3.5 \pm 1.3 \mathrm{~kg} / \mathrm{cm}^{3}$ \\
Diameter & $12 \pm 2.53 \mathrm{~mm}$ \\
Thickness & $7 \pm 1.97 \mathrm{~mm}$ \\
Weight variation test & Complies $( \pm 5 \%)$ \\
Drug content & Complies $(97.16 \%)$ \\
Friability & $0.702 \pm 0.4 \%$ \\
Wetting time & $44 \pm 2.56 \mathrm{~s}$ \\
Water absorption ratio & $45.45 \pm 1.23 \%$ \\
Disintegration time & $40 \pm 2 \mathrm{~s}$ \\
\hline
\end{tabular}

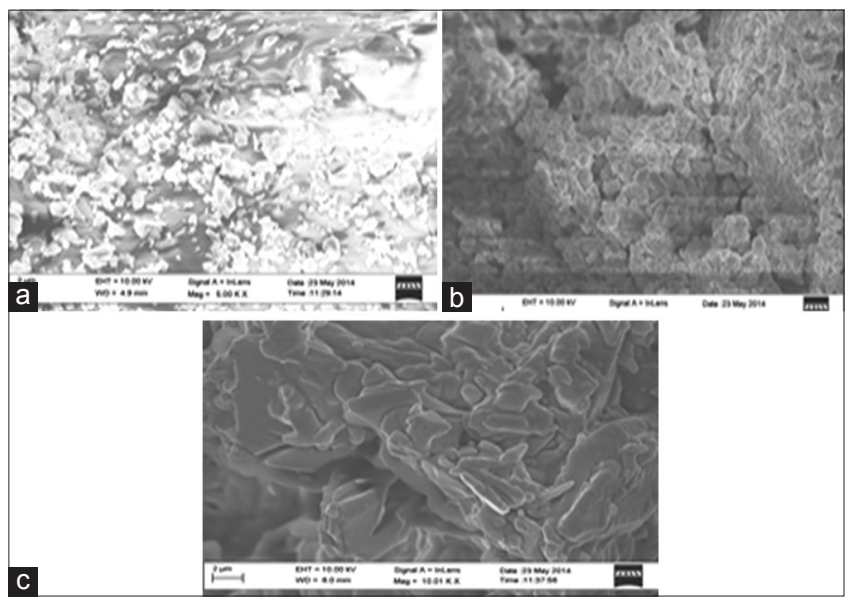

Fig. 9: Scanning electron micrographs of (a) nevirapine,

(b) physical mixtures, and (c) optimized solid dispersion

FDTs. The minimum wetting time and maximum water absorption ratio enable faster disintegration of the tablets, which is the prime criterion for the FDTs (Fig. 10). The wetting time of formulations, i.e., F1, F2, and F3 was found to be 46,48 , and $44 \mathrm{~s}$ and water absorption ratios were found to be $41.44 \%, 41.20 \%$, and $45.45 \%$, respectively.

Above results for pre- and post-compression parameters of tablets reveal that formulation F3 exhibited better flow properties, quick disintegration time, maximum water absorption, and minimum wetting time along with optimum hardness and lower friability as compared to other batches (Table 5). The probable reason for the better results with F3 batch might be due to the optimum amount of superdisintegrant used in the formulations [39].

Dissolution studies for optimized FDTs

The dissolution studies were performed to evaluate the release profile of the drug, which relates the percentage of drug release from its dosage form with the function of time. The desired quality of FDTs was to have 
Table 6: Fitting of drug release from prepared FDTs (F3) to various release kinetic models

\begin{tabular}{|c|c|c|c|c|c|c|c|c|}
\hline \multirow[t]{2}{*}{ Mechanism } & \multicolumn{2}{|c|}{ Zero-order } & \multicolumn{2}{|c|}{ First-order } & \multicolumn{2}{|c|}{ Higuchi } & \multicolumn{2}{|c|}{ Korsmeyer-Peppas } \\
\hline & Slope & $\mathbf{r}^{2}$ & Slope & $\mathbf{r}^{2}$ & Slope & $\mathbf{r}^{2}$ & Slope & $\mathbf{r}^{2}$ \\
\hline F3 & 0.135 & 0.972 & 0.001 & 0.957 & 1.808 & 0.983 & 11.20 & 0.922 \\
\hline
\end{tabular}

FDTs: Fast dissolving tablets

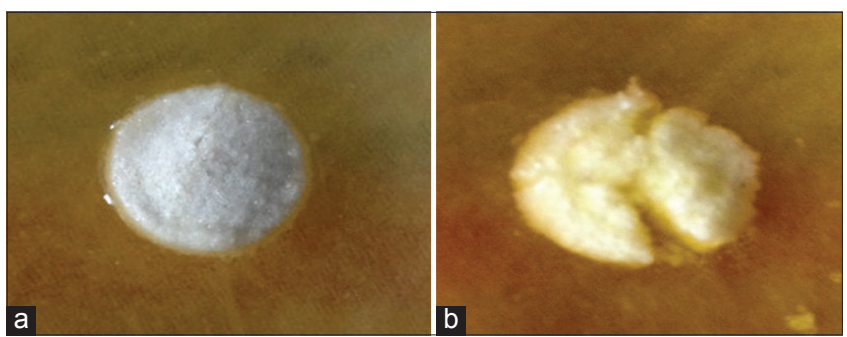

Fig. 10: Wetting time of fast dissolving tablets of batch F3 (a) initial and (b) after $44 \mathrm{~s}$

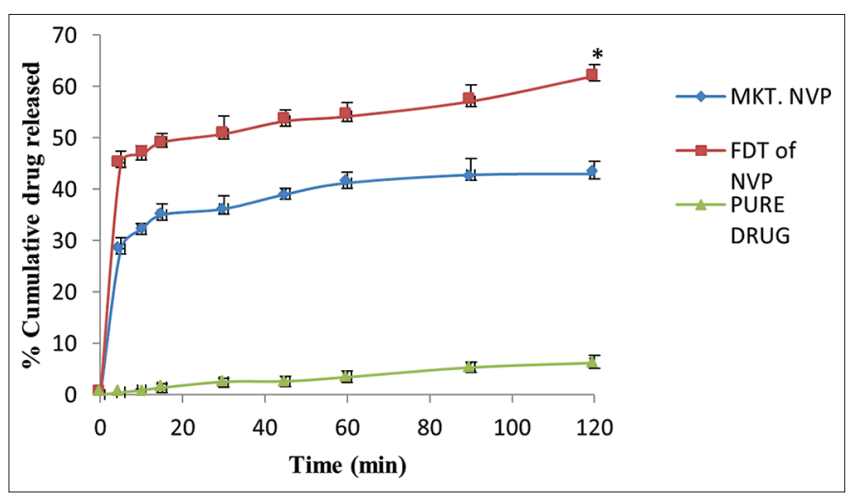

Fig. 11: Dissolution profile of the fast dissolving tablets of nevirapine (NVP) (F3) and marketed formulation of NVP. *p<0.01 compared with pure drug and marketed product, respectively

a maximum release of therapeutic dose at a very minimal time period (Fig. 11). The percentage cumulative release of FDTs and marketed tablets of NVP was compared and revealed that the dissolution rate of the drug of the marketed tablets was low as compared to the FDTs of the NVP $(\mathrm{p}<0.01)$ prepared by direct compression method after the formulation of solid dispersions (F3)

However, the use of superdisintegrant and microcrystalline cellulose in the FDTs of NVP would enhance the drug release from the tablets. Hence, it can be concluded that solid dispersion technology improves the dissolution profile of drug from the prepared FDTs [40].

Mathematical modeling of release kinetics of the prepared FDTs

Table 6 lists the regression parameters obtained after fitting various release kinetic model so the in vitro dissolution data. The $\mathrm{R}^{2}$ value was found to be highest for the Higuchi model, i.e., 0.983 which indicates that the polymer formed a hydrophilic matrix in which drug gets entrapped in an amorphous form. As the matrix depletes, the drug in the amorphous form is available for dissolution.

\section{CONCLUSION}

We focused on solid dispersion as a novel drug delivery carrier for the enhancement of solubility and dissolution rate of NVP. The solid dispersion of drug:polymer ratio, i.e., 1:0.75 showed maximum DE $(75.25 \%)$ and maximum dissolution rate $(79.02 \%)$ in $2 \mathrm{~h}$. Furthermore, FDTs of optimized solid dispersion showed a cumulative drug release of $45.18 \%$ in $5 \mathrm{~min}$ and $62.06 \%$ in $2 \mathrm{~h}$, which is higher than that of marketed tablets of NVP. Therefore, the results from our study suggest that solid dispersion technology can be used as a better alternative to produce FDTs, especially for drugs having poor water solubility.

\section{AUTHORS' CONTRIBUTIONS}

All the authors have contributed equally.

\section{CONFLICTS OF INTEREST}

The authors declare that they have no conflicts of interest to disclose. Moreover, this research did not receive any specific grant from funding agencies in the public, commercial, or not for profit sectors.

\section{REFERENCES}

1. Leuner C, Dressman J. Improving drug solubility for oral delivery using solid dispersions. Eur J Pharm Biopharm 2000;50:47-60.

2. Muller RH, Jacobs C, Kayer O. Nanosuspensions for the Formulation of Poorly Soluble Drugs in Pharmaceutical Emulsion and Suspension. $3^{\text {rd }}$ ed. New York, USA: Marcel Dekker; 2000.

3. Ghareeb MM, Abdulrasool AA, Hussein AA, Noordin MI. Kneading technique for preparation of binary solid dispersion of meloxicam with poloxamer 188. AAPS Pharm Sci Tech 2009;10:1206-15

4. Qian F, Wang J, Hartley R, Tao J, Haddadin R, Mathias N, et al. Solution behavior of PVP-VA and HPMC-AS-based amorphous solid dispersions and their bioavailability implications. Pharm Res 2012;29:2765-76.

5. Kumar A, Sahoo SK, Padhee K, Kochar PS, Sathapathy A, Pathak N. Review on solubility enhancement techniques for hydrophobic drugs. Pharma Glob 2011;3:1-7.

6. Budavari S, editor. The Merck Index, an Encyclopedia of Chemicals, Drugs, and Biologicals. Rahway: Merck; 2000. p. 1114.

7. Sokol RJ, Johnson KE, Karrer FM, Narkewicz MR, Smith D, Kam I. Improvement of cyclosporine absorption in children after liver transplantation by means of water-soluble Vitamin E. Lancet 1991;338:212-5

8. Yadav S, Veena M, Srinivas M. Solid dispersion technique to enhance the solubility and dissolution rate of aripiprazole by fusion method. Int J Pharm Pharm Sci 2016;8:187-92.

9. Mohanraj P, Sarkar DK, Choudhury T, Gauthaman K. A simple and rapid RP-HPLC method for the estimation of NVP in bulk and pharmaceutical dosage forms. J Chem 2008;5:1081-6.

10. Lokamatha KM, Bharathi A, Kumar SM, Rama, RN. Effect of PVPk30 on complexation and dissolution rate of NVP $\beta$-cyclodextrin complexes. Int J Pharm Sci 2008;2:4-13.

11. Shah I, Bhatt S, Yadav A. Enhancement of solubility and dissolution of nebivolol by solid dispersion technique. Int J Pharm Pharm Sci 2014;6:566-71.

12. Sarkar M, Khandavilli S, Panchagnula R. Development and validation of RP-HPLC and ultraviolet spectrophotometric methods of analysis for the quantitative estimation of antiretroviral drugs in pharmaceutical dosage forms. J Chromatogr B 2006;830:349-54

13. Tachibana T, Nakamura A. Method for preparing an aqueous colloidal dispersion of organic materials by using water-soluble polymers: Dispersion of $\beta$-carotene by polyvinylpyrrolidone. Colloid Polym Sci 1965;203:4-9.

14. Khan KA. The concept of dissolution efficiency. J Pharm Pharmacol $1975 ; 27: 48-9$.

15. Bugay DE. Characterization of the solid-state: Spectroscopic techniques. Adv Drug Deliv Rev 2001;48:43-65.

16. Cilurzo F, Minghetti P, Casiraghi A, Montanari L. Characterization of nifedipine solid dispersions. Int J Pharm 2002;242:313-7.

17. Hancock BC, Zografi G. Characteristics and significance of the amorphous state in pharmaceutical systems. J Pharm Sci 1997;86:1-2.

18. Muralidar S, Devala G, Rajesh B, Karunakar R, Nikhat SR. Fast dissolving of celecoxib tablet containing solid dispersion of celecoxib. Int J Pharm Sci Res 2010;9:34-40.

19. Sathali AH, Prakash T. Formulation and evaluation of fast dissolving 
tablets of lamivudine. Int J Pharm Biol Res 2012;5:98-112.

20. Kakade SM, Mannur VS, Ramani KB, Dhada AA, Naval CV, Bhagwat A. Formulation and evaluation of mouth dissolving tablets of losartan potassium by direct compression techniques. Int J Pharm Sci Res 2010;1:290-5.

21. Tiwary V, Kinikar DJ, Pillai K, Gokulan PD. Preparation and evaluation of fast dissolving tablets of celecoxib. J Curr Pharm Res 2010;4:4-11.

22. Ford JL. The current status of solid dispersions. Pharm Acta Helv 1986;61:69-88.

23. Hawi A, Bell G. Preformulation studies of NVP, a reverse transcriptase inhibitor. Pharm Res 1994;11:S236-40.

24. Wacher VJ, Wong S, Wong HT. Peppermint oil enhances cyclosporine oral bioavailability in rats: Comparison with D-alpha-tocopheryl poly(ethylene glycol 1000) succinate (TPGS) and ketoconazole. J Pharm Sci 2002;91:77-90.

25. Kawtikwar PS, Zade PS, Karkar M. Formulation, evaluation and optimization of fast dissolving tablet containing tizanidine $\mathrm{HCl}$. Int $\mathrm{J}$ Pharm Tech Res 2009;1:34-42.

26. Altaf AS, Sivakranth M, Rajasekhar S. Formulation and evaluation of oral fast dissolving tablets of sildenafil citrate. Int J Pharm Sci 2011;3:112-21.

27. Khole SR, Chaudhari PD, More DM. Development and evaluation of melt in mouth tablets of rizatriptan benzoate by sublimation technique. Int J Pharm Sci Res 2011;2:839-48

28. Jain CP, Naruka PS. Formulation and evaluation of fast dissolving tablets of valsartan. Int J Pharm Sci 2009;1:219-26.

29. Rampure MV, Raju SA, Shirsand SB, Swamy PV, Nagendrakumar D, Basawaraj B, et al. Formulation and evaluation of orodispersible tablets of alfuzosin. Int J Pharm Tech Res 2010;2:84-8

30. Chander H, Kumar S, Bhatt B. Formulation and evaluation of fast dissolving tablets of ramipril. Der Pham Sin 2011;2:153-60.
31. Narayana PK, Kumari SK, Narasu L. Solubility and dissolution rate determination of different antiretroviral drugs in different $\mathrm{pH}$ media using UV visible spectrophotometer. Eur J Chem 2008;5:1159-64.

32. Merchant HA, Shoaib HM, Tazeen J, Yousuf RI. Once-daily tablet formulation and in vitro release evaluation of cefpodoxime using hydroxypropyl methylcellulose: A technical note. AAPS Pharm Sci Tech 2006;7:E178-83.

33. Mu L, Feng SS. Vitamin E TPGS used as emulsifier in the solvent evaporation/extraction technique for fabrication of polymeric nanospheres for controlled release of paclitaxel (Taxol). J Control Release 2002;80:129-44.

34. Gujjar PP, Kokil AA, Gaurav YA. Improvement in physicochemical properties of NVP co-crystals. Int J Pharm Technol 2012;4:4831-42.

35. Repka MA, McGinity JW. Influence of vitamin E TPGS on the properties of hydrophilic films produced by hot-melt extrusion. Int J Pharm 2000;202:63-70.

36. Sarkar M, Perumal OP, Panchagnula R. Solid-state characterization of nevirapine. Indian J Pharm Sci 2008;70:619-30.

37. Xie Y, Li G, Yuan X, Cai Z, Rong R. Preparation and in vitro evaluation of solid dispersions of total flavones of Hippophae rhamnoides $\mathrm{L}$. AAPS Pharm Sci Tech 2009;10:631-40.

38. Ruan LP, Yu BY, Fu GM, Zhu DN. Improving the solubility of ampelopsin by solid dispersions and inclusion complexes. J Pharm Biomed Anal 2005;38:457-64.

39. Sharma D. Formulation development and evaluation of fast disintegrating tablets of salbutamol sulphate for respiratory disorders. ISRM Pharm 2013;12:31-40.

40. Basu B, Bagadiya A, Makwana S, Vipul V, Batt D, Dharamsi A, et al. Formulation and evaluation of fast dissolving tablets of cinnarizine using superdisintegrant blends and subliming material. J Adv Pharm Technol Res 2011;2:266-73. 